\title{
Variables Affecting the Creativity of Undergraduate Students at Nakhon Ratchasima Rajabhat University
}

\author{
Banjob Boonchan ${ }^{1,2}$, Phadungchai Pupat ${ }^{1}$, Boonchan Seesan ${ }^{1}$ \\ ${ }^{1}$ DIEd Student in Curriculum Research and Development, Faculty of Industrial Education, King Mongkut's \\ Institute of Technology, Ladkrabang, Thailand \\ ${ }^{2}$ Department of Educational Administration, Nakhon Ratchasima Rajabhat University, Nakhon Ratchasima, \\ Thailand \\ Email: banjobbun@yahoo.com
}

Received 3 November 2015; accepted 5 December 2015; published 8 December 2015

Copyright (C) 2015 by authors and Scientific Research Publishing Inc.

This work is licensed under the Creative Commons Attribution International License (CC BY). http://creativecommons.org/licenses/by/4.0/

(c) (i) Open Access

\section{Abstract}

This descriptive research aims to investigate the construct validity of selected variables affecting the creativity of undergraduate students at Nakhon Ratchasima Rajabhat University. Seven hundred and sixty students participated in this study. They were tested on items relating to their creativity. The results showed that executive administration, teaching, instructional attitudes, motivation, and personality variables affected the creativity of the undergraduates. Creativity consisted of originality, fluency, flexibility, and elaboration. All factor loadings were over 0.30 . After confirmatory factor analysis on creativity, the results showed an acceptable goodness-of-fit $\left(\chi^{2}\right.$ $=0.51, \mathrm{df}=1, p$-value $=0.47497$, RMSEA $=0.000$ ). This shows that creativity measured by the creativity test is in accordance with the empirical data. Executive administration consists of policy, mission, and identity. Teaching consists of objectives, content, activity, and evaluation components. Instructional climate consisted of support, acceptance and participation. Motivation consists of needs, drives, and satisfaction. Personality consists of freedom, trust, and self-esteem. The results of the CFA indicated that each construct was well represented by the items used for the measurements.

\section{Keywords}

Factors, Variables, Creativity, Construct Validity

\section{Introduction}

The National Education Act of BE1 2542 encourages the learning process by means of thinking practice and

How to cite this paper: Boonchan, B., Pupat, P., \& Seesan, B. (2015). Variables Affecting the Creativity of Undergraduate Students at Nakhon Ratchasima Rajabhat University. Creative Education, 6, 2241-2249. 
problem solving both of which contribute to creativity. The aim of the curriculum focuses on the creativity and thinking skills of the students (Kosum et al., 2006). The Education Development Plan (BE 2545-2559) aims to develop Thailand into a moral society in which learning and problem solving contribute to a creative society. Students should develop three core skills, including learning skills, life skills, information and technology skills, which are collectively known as the skills of the 21st century (Trilling \& Fadel, 2009). Systems thinking promotes the understanding that business and human life are systems, where single components affect the other elements of the set. Too many people focus on "snapshots of isolated parts" and, in effect, do not see the forest for the trees. Systems thinking integrates all five disciplines into an organized structure (Senge et al., 2009). The Higher Education Development Plan No. 11 (BE 2555-2559) focuses on producing graduates of quality, with the potential to meet the needs of society, the ability to think critically, to communicate and work together with others with moral responsibility, and a healthy body and mind. This includes the development of teachers with expertise in teaching and research to ensure that graduates achieve the sustainability of the society (Office of the Education Council, 2013).

Creativity is the key to resolving or managing problems effectively. Many educators agree that the idea works very well. Creativity is the most important factor of all. Such new discoveries will benefit people's livelihoods (Torrance, 1994). A consortium led by psychologist Anderson (1996) shows that this leads to a new type of behavior. This is reflected in the 21st century with new verbs associated with Bloom's Taxonomy with which we are now all familiar. For example, changing verbs to describe different levels of behavior, and putting together different ideas or elements can lead to original ideas and more creative thinking.

Creativity can be promoted and developed, both directly and indirectly, but it cannot be forced (Roger, 1998). Everyone is creative in themselves and thus creativity can be developed in both children and adults. It does not require much thought, only a growth in nerve fibre. There are several factors that may be the main reason for the creative development of students, such as executive management, teaching, instructional attitudes, motivation, and personality.

Nakhon Ratchasima Rajabhat University is comprised of six faculties: The Faculty of Education, The Faculty of Humanities and Social Sciences, The Faculty of Industrial Technology, and The Faculty of Health Sciences. The students are both male and female and total of 20,615 people, aged between 18 - 25 years. The programme is for a period of 4 years, except for the Faculty of Education, where students must study for 5 years. Nakhon Ratchasima Rajabhat University has a policy about the quality of its graduates. Its vision is to be a leader in education, train teachers and education personnel, and promote research into local development. Thus, the aim is to enhance the quality of people and society so that they have the potential to compete both nationally and internationally. Its mission is to produce graduates with knowledge and of sound morality. The creativity of students is an important feature that will strengthen the community in its work and benefit local development.

The academic staff at the university play a primary role in teaching and research in line with the National Education Act BE 2542 and the policy of the university is to promote the creativity of the students. We therefore studied the causal model of the variables that influenced the creativity of the undergraduates at Nakhon Ratchasima Rajabhat University. On this basis we intend to draw up a plan which will develop the creativity of the students and which may also be used as information to find solutions to the various problems experienced by students, administrators, faculty, families and society. Further collaboration with all those involved may be necessary.

\section{Literature Review}

People naturally accept the idea that creativity is necessary for the future in every field. If so, what is creativity? Creativity is the ability to generate new, surprising and valuable ideas or artifacts (Boden, 2004). Gardner (2007) explained that people must have creative minds and must develop them for the future, "Going beyond existing knowledge and syntheses to pose new questions, offering new solutions, fashioning works that stretch existing genres or configure new ones; creating builds on one or more established disciplines and requires an informed field to make judgments of quality and acceptability.” Lubart (1999) explained that the eastern and western conceptions of creativity are not identical. The eastern view of creativity did not include humor and aesthetic sensitivity as did the Western view, but did include social and moral aspects of creativity. Clearly, culture influences people's perception of creativity. There is a general consensus among researchers of creativity about what creativity is. Most researchers define creativity as being a product and a process having novelty (i.e., new, orig- 
inal) and appropriateness (i.e., usefulness, adaptation) (Sternberg \& Lubart, 1996; Vernon, 1989). Even with the agreed definitions, the approaches to explaining creativity are diverse.

In recent decades, the research effort has spread beyond psychologists to include cognitive scientists, sociologists, anthropologists, historians, education researchers, engineers, managers, and systems analysts. This shift has led to a change in the research on creativity by focusing on methodologies. Today, an important trend in the research on creativity is to uncover the key components that influence creative ideas (Amabile, 1996). Through reviewing the main findings in recent research trends (key components and domain-specific creativity), we can explain the models of the various components to explain creativity in terms of two separate categories. Firstly, the individual approach to creativity has a focus on cognition through examining the cognitive abilities and processes involved in creative thinking or a focus on the characteristics of creative people. Secondly, the contextual approach to creativity, as an integrated componential model, gives emphasis to examining extended interaction between individuals and situations.

The first period of the cognitive approach to creativity started with the work of Guilford (1991), who stated that specifically divergent thinking is related to factors of fluency, flexibility, originality and elaboration. The three kinds of fluency are concerned with the products of units, relations, and systems. There are two kinds of flexibility which are concerned with classes and transformations, into which the category of originality also fits. Elaboration has to do with implications. In 1977, Guilford defined creativity as creative problem solving.

Studies of creative people have focused on the traits of the creative personality (Martindale, 1989). To find out the disposition of creative people, researchers of personality usually used nomination and interview as research techniques. Sternberg \& Lubart (1996) found that creative people tolerate ambiguity, are willing to overcome obstacles, are open to new experience, take risks, encourage conviction, challenges, and enterprise. Feist (1999) explored the personalities of creative people, who were both artistic and scientific. He concluded that creative people have a tendency to be open to fresh experience, and are self-confident/self-accepting. Also, creative people are not conventional, are driven, ambitious, and impulsive. In Feist's study, the most interesting finding was that creative people in art were more emotionally unstable and less socialized than creative people in science. People with creativity in science showed conscientiousness and shared ideas with other scientists.

Even though researchers of personality explain the various traits of creative experts, they still have difficulty in determining the key common components of personality relating to creativity across domains. Sawyer (1995) mentioned that psychologists of personality did not identify which characteristics distinguish creative people from ordinary people. Through a review of the literature about creative people's personalities, the researcher found that a common trait of creative people is motivation. Amabile (1996), who studied the personality of creative people, concluded that people with intrinsic task motivation have a high possibility of showing creative performance.

The socio-cultural approach in research about creativity started from Amabile's studies (1996). She emphasized the fact that the confluence of a variety of environmental and personal variables is necessary for creativity. Amabile and her colleagues concluded that intrinsic motivation across domains plays a crucial role in creative performances and products.

Through this review of literature about the individual approach and contextual approach to creativity, the researcher found five key variables: a) executive administration (i.e., policy, mission, and identity), b) teaching (i.e., objectives, content, activity, and evaluation), c) instructional attitudes (i.e., support, acceptance, and participation), d) motivation (i.e., needs, drives, and satisfaction), and e) personality (i.e., freedom, trust, and selfesteem). Most researchers agreed that the five categories of these components strongly influence each other with regard to creativity. Even in the framework consisting of five categories of components, most researchers did not include construct validity among these components. A few researchers have explored the partial relations between the various components. The researcher found that comprehensive studies which explore construct validity of the twenty components are rare. Therefore, there are still a lot of questions which remain unanswered.

The purpose of this study is to investigate the factors of the variables affecting the creativity of undergraduate students at Nakhon Ratchasima Rajabhat University and to analyze their construct validity by confirmatory factor analysis.

\section{Methodology}

The study was conducted in two phases. The first phase was to investigate the variables affecting creativity 
through documentary analysis and by focusing on group discussions. The second phase was to investigate the construct validity of factors of the selected variables.

\subsection{The Sample}

In the first phase, nine experts from both inside and outside Nakhon Ratchasima Rajabhat University took part in a group discussion. All the experts met the following requirements: they were doctoral holders on curriculum and instruction, or curriculum research and development, or educational measurement and evaluation, or educational administration, or experienced in using creativity measurements, or have been teaching for at least one year at tertiary level. In the second phase, respondents were 760 regular undergraduate students selected by stratified random sampling by their faculty. Among the 760 respondents, there were 190 male (25\%) and 570 female (75\%). The respondents' age ranged from 18 to 23 years and the average age was 21 years.

\subsection{Instrument}

The instruments used in this study were a creativity test with a reliability of 0.914 and a questionnaire on variables affecting creativity with a reliability of $0.925,0.949,0.941,0.899$, and 0.925 , such as executive administration, teaching, instructional climate, motivation and personality, respectively. In order to facilitate the collection of data, the researcher conducted creativity tests and distributed hard copies of a questionnaire to the students. The creativity test consisted of 4 dimensions, namely originality, fluency, flexibility, and elaboration. The questionnaires which included 66 items, were collected from 760 respondents through a self-designed five-point Likert scale (ranging from Strongly Agree-5 to Strongly Disagree-1). A reliability test was conducted to measure the consistency of the measuring instrument. The reliability of the measures was assessed with the use of Cronbach's Alpha. Cronbach's alpha reliability estimates are used to measure the internal consistency of the scales. As a general rule a coefficient greater than or equal to 0.70 is considered acceptable and is a good indicator of reliability.

\subsection{Data Analysis}

The data collected were refined and processed by SPSS 16.0 software. Several methods of analysis were used in this research to find out and test the impact of the variables affecting creativity. After assessing the reliability of the measurements by Cronbach Alpha and the coefficient, then removing unreliable variables, confirmatory factor analysis was used. This method is very useful in determining the construct variables for the research as well as in finding the relationship between them. The researcher used confirmatory factor analysis for all 6 measurement models consisting of creativity, executive administration, teaching, instructional climate, motivation, and personality in order to investigate the construct validity of factors for each latent variable to establish the true factors in accordance with the theories of LISREL 8.80 .

\section{Results}

\subsection{The Selected Variables}

The variables affecting the creativity of undergraduates at Nakhon Ratchasima Rajabhat University consisted of executive administration, teaching, instructional climate, motivation, and personality.

\subsection{The Construct Validity of Variables}

1) Creativity consisted of originality, fluency, flexibility, and elaboration components. All factor loadings were over 0.30 . After confirmatory factor analysis on creativity, the results showed an acceptable goodness-offit $\left(\chi^{2}=0.51, \mathrm{df}=1, p\right.$-value $=0.47497$, RMSEA $\left.=0.000\right)$. This shows that creativity measured by the creativity test was in accordance with empirical data.

2) Executive administration consisted of policy, mission, and identity components. All factor loadings were over 0.30. After confirmatory factor analysis on executive administration, the results showed an acceptable goodness-of-fit $\left(\chi^{2}=0.00, \mathrm{df}=0, p\right.$-value $=1.00000$, RMSEA $\left.=0.000\right)$. This shows that the executive administration measurement model was in accordance with the empirical data.

3) Teaching consisted of objectives, content, activity, and evaluation components. All factor loadings were 
over 0.30 . After confirmatory factor analysis on creativity, the results indicated an acceptable goodness-of-fit $\left(\chi^{2}\right.$ $=5.49, \mathrm{df}=2, p$-value $=0.06441, \mathrm{RMSEA}=0.048)$. This shows that the teaching measurement model was in accordance with empirical data.

4) Instructional consisted of support, acceptance, and participation components. All factor loadings were over 0.30 . After confirmatory factor analysis on creativity, the results indicated an acceptable goodness-of-fit $\left(\chi^{2}=\right.$ $0.00, \mathrm{df}=0, p$-value $=1.00000$, RMSEA $=0.000$ ). This shows that the instructional climate measurement model was in accordance with the empirical data.

5) Motivation consisted of needs, drives, and satisfaction components. All factor loadings were over 0.30 . After confirmatory factor analysis on motivation, the results showed an acceptable goodness-of-fit $\left(\chi^{2}=0.00\right.$, df $=0, p$-value $=1.00000$, RMSEA $=0.000$ ). This shows that motivation measurement model was in accordance with the empirical data.

6) Personality consisted of freedom, trust, and self-esteem. All factor loadings were over 0.30 . After confirmatory factor analysis on personality, the results indicated an acceptable goodness-of-fit $\left(\chi^{2}=0.00, \mathrm{df}=0\right.$, $p$-value $=1.00000$, RMSEA $=0.000$ ). This shows that the personality measurement model was in accordance with the empirical data. The results of the CFA indicate that each construct was well represented by the items used in the measurements.

\section{Discussion}

The research findings are shown as follows:

\subsection{The Selected Variables}

The results revealed that executive administration, teaching, instructional climate, motivation, and personality variables affected the creativity of the undergraduate students at Nakhon Ratchasima Rajabhat University. The discussion of each variable is as follows:

1) Executive administration was found by the experts in the group discussion to affect the creativity of undergraduate students at Nakhon Ratchasima Rajabhat University because, as the academics pointed out, it is the management of the affairs of an organization, such as a business or institution, the duty or duties of an administrator in exercising the executive functions of his position in all university activities. There are three major components to executive administration: policy, mission, and identity. Policy is a set of ideas or a plan for action followed by a dean, head of department, or a group of faculty in the university. For example, policy has an effect on creating educational opportunities, improving the quality of graduates, the training and development of teachers and education personnel, developing the university towards excellence, and strengthening the community. Mission is a written declaration of a university's core purpose and focus that normally remains unchanged over time. For example, the university provides various activities to promote and develop the creativity of the students. Identity means who a person is, or the qualities of a person or group that make them different from others or the state of having unique identifying characteristics held by no other person or thing. Nakhon Ratchasima Rajabhat University's identity is depending on its local settings.

2) Teaching is the activities of the faculty which are comprised of 5 main factors, such as behavioral objectives, subject matter, instruction, evaluation, and improving teaching. Behavioral objectives can be defined in terms of students' learning the forms of self-expression or acts that can be observed. Subject matter means knowledge, learning experience, practical skills, attitudes, values, process, the preliminary ideas, concepts, and thinking systems. Instructional activity is the lesson plan which needs to be implemented. Instructional evaluation is examination of all data learnt by the learner so that their learning progress can be assessed. Instructional improvement means correction, change, encouragement for development, learning, and perception of change. Academics and researchers who have examined the factors of variables affecting the creative thinking of undergraduate students are, for example, Vilaipis (2004), Samakwong (2005), Veerachareonkij (2006), Boonwan (2009), and Yokubon (2012).

3) Motivation is defined as the process that initiates, guides, and maintains goal-oriented behaviors. Motivation is what causes us to act, whether it is getting a glass of water to reduce thirst or reading a book to gain knowledge. There are three major components to motivation: needs, drive, and satisfaction. Need is a motivating force that compels action for its satisfaction. Needs range from basic survival needs (common to all human beings) satisfied by necessities, to cultural, intellectual, and social needs (varying from place to place and age 
group to age group). Needs are finite, but in contrast, wants (which spring from desires or wishes) are boundless. For example, to develop the creativity of the students requires a response in terms of their expectations and their desire to continue their studies. Drive is the desire for self-actualization, need for achievement, belongingness, and status, and other such motivations based on thought patterns and social influences instead of on fundamental biological needs (food, security, and procreation). For example, students are encouraged by teachers and friends to develop their creativity on a regular basis. Satisfaction is the level of approval when comparing a product's perceived performance with his or her expectations. Also it could refer to discharge, extinguishment, or retirement of an obligation to the acceptance of the obligor, or fulfillment of a claim. While satisfaction is sometimes equated with performance, it implies compensation or substitution whereas performance denotes doing what was actually promised. For example, students have positive feelings toward themselves when they achieve creative development. Academics and researchers who have investigated the motivation variable affecting creative thinking of undergraduate students include Panjamawat (2005), Paksanchai (2008), Boonwan (2009), Yokubon (2012), Sternberg (2003), and Niu \& Sternberg (2003).

4) Personality is the combination of characteristics or qualities that form an individual's distinctive character. There are three major components to personality: personal freedom, self-confidence and self-esteem. Freedom stands for something greater than just the right to act, it also stands for securing for everyone an equal opportunity for life, liberty, and the pursuit of happiness. For example, students feel that they can develop their creativity, in spite of the requirements of the university. Self-confidence means reliance on the integrity, strength and ability of a person or thing; self-confidence reflects a person's overall subjective emotional evaluation of his or her own worth. It is a judgment of oneself as well as an attitude towards oneself. For example, students believe that they have the potential to be able to do a good job of work. Self-esteem encompasses beliefs and emotions such as triumph, despair, pride, and shame. Self-esteem is the positive or negative evaluations of the self, as in how we feel about ourselves. Self-esteem is attractive as a social psychological construct because researchers have conceptualized it as an influential predictor of creativity. Self-esteem can apply specifically to a particular dimension or a global extent. Psychologists usually regard self-esteem as an enduring personality characteristic, though normal, short-term variations also exist. Synonyms or near-synonyms of self-esteem include: self-worth, self-regard, self-respect, and self-integrity. For example, students think that they have been accepted by the people in a society that is creative. Academics and researchers who viewed the personality variable affecting the creative thinking of undergraduate students include Panjamawat (2005), Boonwan (2009), Niu \& Sternberg (2003).

5) Instructional attitude is an aspect of the educational environment defined by the characteristic demands of the classroom as perceived by the students to whom they are directed. There are three major components to instructional attitude: the teacher's support, the teacher's acceptance, and the student's participation. A teacher's support means to give help give encouragement to students because teachers want him or her to succeed. For example, a lecturer gives students assistance and guidance in activities which will develop creativity. Instructors focus on creative development activities resulting from the needs of students. A teacher's acceptance means the act of taking or receiving something offered, or giving it a favorable reception or approval. For example, instructors express an appreciation of the success of their students in their creative development. A student's participation means an act or instance of participating, the fact of taking part, as in some action or attempted action of students. Students participate in the evaluation of their creativity and in the planning of creative development activities. Academics and researchers who investigated instructional attitude as a variable affecting the creative thinking of undergraduate students include Samakwong (2005), Panjamawat (2005), and Boonwan (2009).

\subsection{The Construct Validity of Variables}

1) Creativity consists of originality, fluency, flexibility, and elaboration. All factor loadings were over 0.30 . After confirmatory factor analysis on creativity, the results showed an acceptable goodness-of-fit $\left(\chi^{2}=0.51\right.$, $\mathrm{df}$ $=1, p$-value $=0.47497$, RMSEA $=0.000)$. This shows that the creativity measured by the creativity test is in accordance with the empirical data. Creativity can be divided into divergent and convergent thinking, although the researcher argues that essentially the same processes are involved in both. Divergent thinking is measured using the Torrance test of creative thinking (TTCT). TTCT consists of both verbal and figurative parts. Divergent thinking is also measured by Guilford's Alternate Uses Task in which one has to come up with as many uses as possible for a common household item, such as a brick. These creativity test results are scored keeping in 
mind a number of different creativity criteria. The most common (common to all of the above) criteria are: Flexibility, which captures the ability to cross boundaries and to make remote associations. This is measured by the number of different categories of ideas generated; Originality which measures how statistically different or novel the ideas are compared to a comparison group. This is measured by the number of novel ideas generated; Fluency, which captures the ability to come up with many diverse ideas quickly. This is measured by the total number of ideas generated; Elaboration, which measures the amount of detail associated with an idea. Elaboration means focusing on each solution/idea and developing it further. Academics and researchers who investigated creativity as composed of four components include Rojsuparat (2004), Panmanee (2007), Moonkam (2007), Dalton (1988), and Guilford (1991).

2) Executive administration consists of policy, mission, and identity. All factor loadings were over 0.30 . After confirmatory factor analysis on executive administration, the results showed an acceptable goodness-of-fit $\left(\chi^{2}\right.$ $=0.00, \mathrm{df}=0, p$-value $=1.00000$, RMSEA $=0.000$ ). This shows that the executive administration measurement model is in accordance with empirical data. Thus, all three factors must be true components of executive administration that reflection on the management of administrators with regard to university policy, mission, and identity. All of these variables have an effect on the creative activities of the students.

3) Teaching consists of objectives, content, activity, and evaluation. All factor loadings were over 0.30 . After confirmatory factor analysis on creativity, the results showed an acceptable goodness-of-fit $\left(\chi^{2}=5.49 \mathrm{df}=2\right.$, $p$-value $=0.06441$, RMSEA $=0.048)$. This also shows that the teaching measurements are in accordance with the empirical data. Thus, all four factors are the true components of teaching that reflect on teaching such as when a teacher asks students to explain the characteristics of what has been studied.

4) Instructional attitude consists of support, acceptance, and participation. All factor loadings were over 0.30 . After confirmatory factor analysis on creativity, the results showed an acceptable goodness-of-fit $\left(\chi^{2}=0.00\right.$, df $=0, p$-value $=1.00000$, RMSEA $=0.000$ ). This shows that the measurements of instructional attitude model are in accordance with the empirical data. Thus, all three factors are true components that reflect on instructional attitude, such as the teacher provides a lot of materials to the students to help them with their studies and the teacher makes the students feel free to ask questions and share ideas in the classroom.

5) Motivation consists needs, drives, and satisfaction. All factor loadings were over 0.30. After confirmatory factor analysis on motivation, the results showed an acceptable goodness-of-fit $\left(\chi^{2}=0.00, \mathrm{df}=0, p\right.$-value $=$ 1.00000, RMSEA $=0.000$ ). This shows that the measurements of the motivation model are in accordance with the empirical data. Thus all three factors are true components that reflect on motivation, such as the more difficult the problem, the more a particular student enjoys trying to solve it, curiosity is the driving force behind much of what such a student does.

6) Personality consists of freedom, trust, and self-esteem. All factor loadings were over 0.30 . After confirmatory factor analysis on personality, the results showed an acceptable goodness-of-fit $\left(\chi^{2}=0.00, \mathrm{df}=0, p\right.$-value $=$ 1.00000 , RMSEA $=0.000$ ). This shows that the measurements of the personality model are in accordance with the empirical data. Thus, the results of the CFA indicate that each construct is well represented by the items used in the measurements. Therefore, all three factors are true components of the model that reflect on personality, for example, the students' feeling that they can develop their creativity in spite of the restrictions of the university and the students' belief that they have the potential to be able to do a good job of work in the future.

\section{Conclusion}

The executive administration, teaching, instructional climate, motivation, and personality were major variables affected the creativity of the undergraduate students at Nakhon Ratchasima Rajabhat University. Each variable consisted of particular factors with construct validity. As a result, the results showed an acceptable goodnessof-fit. Regarding the CFA, each variable has construct validity which well represented by the items used in the measurements. Hence, the university, instructors, and parents as well as students, should play their key roles in promoting students' creativity.

\section{Implication}

1) The study should include other variables that have effects on undergraduate students' creativity at Nakhon Ratchasima Rajabhat University such as living conditions, economic status of the family, rearing, emotional intelligence, reasoning ability, and learning achievements. 
2) There should be a study of creativity development format of the undergraduate students of Nakhon Ratchasima Rajabhat University.

3) The study of students' creativity development should be used mixed method research design both quantitatively and qualitatively.

\section{References}

Amabile, T. (1996).Creativity in Context. Boulder, CO: Westview Press.

Anderson, G. (1996). Learning Contracts: A Practical Guide. London: Kogan Page.

Boden, M. A. (2004). The Creative Mind: Myths and Mechanisms (2nd ed.). New Fetter, London: Routledge.

Boonwan, D. (2009). Variables Influencing Creativity of Grade 6 Students under the Jurisdiction of Suphan Buri Educational Service Area Office. M.Ed. Thesis, Kanchanaburi: KanchanaburiRajabhat University.

Dalton, D. R. (1988). Antecedents of Grievance Filing Behavior: Attitude/Behavioral Consistency and the Union Steward. The Academy of Management Journal, 25, 158-169. http://dx.doi.org/10.2307/256031

Feist, G. J. (1999).The Influence of Personality on Artistic and Scientific Creativity. In R. J. Sternberg (Eds.). Handbook of Creativity. London: Cambridge University Press.

Gardner, H. (2007). Five Minds for the Future. Cambridge: Harvard Business Review.

Guilford, J. P. (1991). Creativity. American Psychologist, 5, 444-454. http://dx.doi.org/10.1037/h0063487

Kosum, S. et al. (2006). Teaching Children to Think. Bangkok: Vichakarn Press.

Lubart, T. I. (1999). The Concept of Creativity: Prospects and Paradigms. In R. J. Sternberg (Eds.), Handbook of Creativity. London: Cambridge University Press.

Martindale, C. (1989). Personality, Situation, and Creativity. New York: Plenum. http://dx.doi.org/10.1007/978-1-4757-5356-1_13

Moonkam, S. (2007). Fully Equipped to Think. Bangkok: Partnership Prints.

Niu, W., \& Sternberg, R. J. (2003). Societal and School Influences on Student Creativity: The Case of China. Psychology in the Schools, 40, 103-114. http://dx.doi.org/10.1002/pits.10072

Office of the Education Council (2013). Thailand Education State for Population Report. Bangkok: Pim Dee Publishing House.

Paksanchai, M. (2008). The Development of the Cause and Effect Model of Creativity of Junior High School Students of the Archdiocese, Bangkok. M.Ed. Thesis, Bangkok: Chulalongkorn University.

Panjamawat, T. (2005). Causal Model of the Variables That Influence Student Creativity. M.Ed. Thesis, Bangkok: Chulalongkorn University.

Panmanee, A. (2007). Psychological Creative Teaching. Bangkok: Yaimai Educated Press.

Rojsuparat, P. (2004). A Comparative Study of Creativity of Early Childhood on Drawing Activity between Individual and Selective. M.Ed. Thesis, Bangkok: Srinakharinwirot University.

Samakwong, S. (2005). Comparative Analysis of Model Variables That Influence on Mathematical Creations of Grade 5 Students under the Jurisdiction of Roiet Educational Service Area Office with PAQ Analysis and PAL. M.Ed. Thesis, Mahasarakam: Mahasarakam University.

Sawyer, R. K. (1995). Creative Insight: The Social Dimension of a Solitary Moment. London: MIT Press.

Senge, P., Cambron-McCabe, N., Lucas, T., Smith, B., Dutton, J., \& Kleiner, A. (2009). Schools That Learn a Fifth Discipline Fieldbook for Educators, Parents, and Everyone who Cares about Education. New York: Doubleday/Currency.

Sternberg, R. J. (2003). Wisdom, Intelligence, and Creativity Synthesized. London: Cambridge University Press. http://dx.doi.org/10.1017/CBO9780511509612

Sternberg, R. J., \& Lubart, T. I. (1996). Investing in Creativity. American Psychologist, 51, 677-688. http://dx.doi.org/10.1037/0003-066X.51.7.677

Torrance, E. P. (1994). Creativity: Just Wanting to Know. Pretoria: Benedict Books.

Trilling, B., \& Fadel, C. (2009). 21st Century Skills: Learning for Life in Our Times. San Francisco, CA: Jossey-Bass, a Wiley Imprint.

Veerachareonkij, T. (2006). A Comparison of Critical Thinking and Creativity between Students with Different Learning Styles. M.Ed. Thesis, Bangkok: Chulalongkorn University.

Vernon, P. E. (1989). The Nature-Nurture Problem in Creativity. New York: Plenum Publishing Corp.

Vilaipis, V. (2004). Factors Affecting Mathematics Creativity of Grade 3 Students under the Jurisdiction of Roiet Educa- 
tional Service Area Office: Multilevel Analysis by Using Hierarchical Linear Modeling. M.Ed. Thesis, Mahasarakam: Mahasarakam University.

Yokubon, N. (2012). Factors Affecting the Achievement of Science. Grade 6 Students at Demonstration Schools under the Commission on Higher Education, Ministry of Education. Journal of Education and Social Development, 8, 56-62. 